\title{
MULTIPLE MIDLINE INTRACRANIAL GERMINOMA MANAGED BY NEUROENDOSCOPY
}

\author{
Joacil Carlos da Silva', Frederico de Melo Tavares de Lima', Igor Vilela Faquini', \\ Leonardo Ferraz Costa', Marcelo Moraes Valença ${ }^{2}$, Roberto José Vieira de Mello ${ }^{3}$
}

Germinomas belong to the class of germ cell tumors that also comprise embryonal cell carcinoma, yolk sac tumor, teratoma (mature and immature) and choriocarcinoma. Extragonadal germ cell tumors typically arise in midline locations. The most common sites of origin in adults are the anterior mediastinum, retroperitoneum and the pineal and suprasellar regions of the brain'. Multiple primary intracranial germ cell tumors are uncommon. Only 5-10\% of all germinomas are found as synchronous lesion in pineal and suprasellar region'. The cerebellar location is extremely rare with nine cases previously reported ${ }^{2}$.

The simultaneous midline triple location (pineal, suprasellar and cerebellum) was never documented ${ }^{1-6}$.

\section{CASE}

A 17-years-old male presented with anorexia, ataxia and paresis of upward gaze during a period of two months. Symptoms worsened one week before admission with intracranial hypertension signs and altered awareness. Neurological examination revealed papilledema and there was restriction of upward gaze and convergent nystagmus on attempted upgaze (Parinaud's syndrome). The patient had normal mental development and secondary sexual characters.

Magnetic resonance imaging (MRI) demonstrated obstructive hydrocephalus and three midline contrast-enhancing lesions located at pineal, suprasellar region and posterior fossa (Figure) There were no spine lesions. Cerebrospinal fluid examination was normal without atypical cells. The tumor markers human chorionic gonadotropin and $\alpha$-fetoprotein in serum and cerebrospinal fluid had normal values.

Endoscopic third-ventriculostomy was performed and during the same procedure the suprasellar tumour was partially resected. Histological examination of the tissue was compatible with germinoma. The patient received radiotherapy with an excellent outcome result.

\section{DISCUSSION}

There is always controversy about the therapeutic modalities of intracranial germ cell tumors. Some neurosurgeons insist that histological verification is crucial before any treatment. On the other hand, the so-called diagnostic or blind radiotherapy is also advocated as a safer option?'

This more conservative approach was especially favored by the Japanese, because the high preponderance of radiosensitive germinomas in that population provided support for this rationale $e^{7,8}$. Unfortunately, this strategy can lead to unnecessary and potentially harmful radiation for many patients with benign and radiation-resistant tumors ${ }^{9}$.
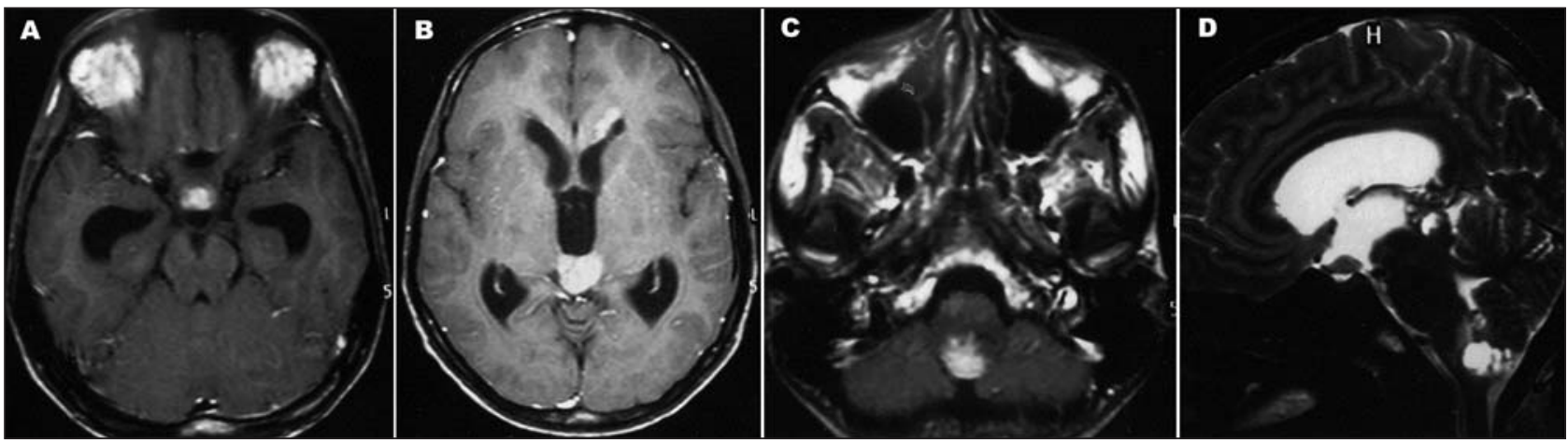

Figure. (A) (B) (C): Contrast enhanced T1 axial MRI. (D) Sagittal T2 MR, note the midline distribution of the three lesions.

\section{GERMINOMA INTRACRANIANO MÚLTIPLO TRATADO POR NEUROENDOSCOPIA}

'Department of Neurological Surgery, Restauração Hospital, Recife PE, Brazil; ${ }^{2}$ Department of Neurological Surgery, Federal University of Pernambuco, Recife PE, Brazil; ${ }^{3}$ Department of Pathology, Federal University of Pernambuco, Recife PE, Brazil.

Received 31 July 2008, received in final form 3 October 2008. Accepted 13 November 2008.

Dr. Joacil Carlos da Silva - Rua Agenor Lopes 424 / 701 - 51021-110 Recife PE - Brasil.E-mail: joacil_carlos@hotmail.com 
Tissue diagnosis can be obtained by a stereotactic biopsy, craniotomy or neuroendoscopy. The approach is influenced by clinical and radiographic features and the surgeon's degree of experience with the procedures ${ }^{7}$. The obvious advantage of open resection is the ability to obtain larger amounts of tissue to histological analysis. The clinical advantages of tumor debulking are less apparent with malignant tumors like the germinoma ${ }^{1,7}$.

The relative technical ease of performing stereotactic biopsy procedures should be viewed cautiously with regard to pineal region lesions. There is an increased risk or hemorrhage from several mechanisms, including bleeding in highly vascular tumors or damage to the deep venous system with catastrophic intraventricular hemorrhage and acute hydrocephalus. ${ }^{10}$

Endoscopic biopsy through the ventricles has been reported as an alternative method of securing a tissue diagnosis and typically this procedure is combined with a third-ventriculostomy. Diagnostic sensitivity for endoscopic biopsy is reported as $75 \%{ }^{11}$.

Neuroendoscopy is a safe and minimally invasive approach to these lesions. The possibility of direct hemostasis with bipolar or monopolar coagulation gives a huge superiority to stereotactic biopsy. Neuroendoscopic procedures can permit a precise histological diagnosis of intracranial germinomas and are also cost-effective in the management of hydrocephalus avoiding a more expensive shunt procedure.

\section{REFERENCES}

1. van Battum P, Huijberts M, Heijckmann A, Wilmink J, Nieuwenhuijzen KA. Intracranial multiple midline germinomas: is histological verification crucial for therapy? Neth J Med 2007;65:386-389.

2. Maiuri F, Cappabianca P, Del Basso De Caro M, Esposito F, de Divitiis E. Primary cerebellar germinomas of the posterior fossa. Br J Neurosurg 2004;18:284-289.

3. Masuzawa T, Shimabukuro $\mathrm{H}$, Nakahara N, Iwasa H, Sato F. Germ cell tumors (germinoma and yolk sac tumor) in unusual sites in the brain. Clin Neuropathol 1986;5:190-202.

4. Nakano S, Uehara H, Kinoshita K. Unusual clinical presentation of a presumed pineal germinoma with two disseminated lesions. Neurosurgery 1988;23:235-236.

5. Ng H, Poon W. Primary germinoma of the posterior fossa with CSF and extracranial metastases. Br J Neurosurg 1990;4:239-242.

6. Guerrero-Vazquez S, Armesto-Perez V, Macia-Suarez D, Branas-Fernandez FM. [Simultaneous suprasellar and pineal germinoma: a case report]. Rev Neurol 2008;46:411-415.

7. Kanamori M, Kumabe T, Tominaga T. Is histological diagnosis necessary to start treatment for germ cell tumours in the pineal region? J Clin Neurosci 2008;15:978-987.

8. Koide O, Watanabe Y, Sato K. Pathological survey of intracranial germinoma and pinealoma in Japan. Cancer 1980;45:2119-2130.

9. Sakai N, Yamada H, Andoh T, Hirata T, Shimizu K, Shinoda J. Primary intracranial germ-cell tumors. A retrospective analysis with special reference to long-term results of treatment and the behavior of rare types of tumors. Acta Oncol 1988;27:43-50.

10. Kreth FW, Schatz CR, Pagenstecher A, Faist M, Volk B, Ostertag CB. Stereotactic management of lesions of the pineal region. Neurosurgery 1996;39:280-291.

11. Al-Tamimi $Y Z$, Bhargava D, Surash S, et al. Endoscopic biopsy during third ventriculostomy in paediatric pineal region tumours. Childs Nerv Syst 2008;24:1323-1326. 